Original Article

\title{
Relationship between the phases of the menstrual cycle and the transversus abdominis muscle
}

\author{
Hitomi Ubukata, MS ${ }^{1,2)^{*}}$, Ayana Matsumura, PTS ${ }^{1)}$ \\ 1) Department of Physical Therapy, Faculty of Health Care, Takasaki University of Health and Wel- \\ fare: 501 Nakaoruicho, Takasaki City, Gunma 370-0033, Japan \\ 2) Department of Physical Therapy, Health and Welfare Science Course, Graduate School of Interna- \\ tional University of Health and Welfare, Japan
}

\begin{abstract}
Purpose] This study investigated changes in the thickness of the transversus abdominis muscle at various stages of the menstrual cycle. [Subjects] The subjects were 15 young healthy females with regular menstrual cycles. [Methods] A regular menstrual cycle was defined as a 28-day cycle comprising 3 phases: the menstrual phase, the follicular phase, and the luteal phase. For the purpose of the study, measurements were taken at day 3 (menstrual phase), day 12 (follicular phase), and day 21 (luteal phase) of the cycle. An ultrasonic imaging diagnostic device (MyLab 25) and a linear expression probe were used for measurement of the transversus abdominis muscle. [Results] There were no significant differences in the variation rate of the thickness of the muscle at any phase of the menstrual cycle. [Conclusion] The results suggested that the sex hormones associated with the menstrual cycle do not affect the contractility or changes in the thickness of the transversus abdominis muscle. For the reasons stated above, there is little need to consider the menstrual cycle when measuring muscle thickness in physical therapy scenarios because the transversus abdominis muscle does not depend on the menstrual cycle.

Key words: Ultrasonic imaging, Menstrual cycle, Sex hormone
\end{abstract}

(This article was submitted Jun. 23, 2014, and was accepted Oct. 1, 2014)

\section{INTRODUCTION}

Women promote the accumulation generation of estrogen and fat due to the influence of sex hormones on or after puberty. Also, breast development and menstruation begins at approximately 12 years old ${ }^{1,2)}$. Menses is defined as hemorrhage from the uterus that ends naturally after some days and repeats periodically; it indicates the onset of a female's reproductive years. The menstrual cycle is approximately 1 month long and can be divided into 4 phases: the menstrual phase, the follicular phase, the ovulation phase, and the luteal phase. The menstrual cycle is mainly regulated by changes in the levels of the follicular hormone (estrogen) and the luteal hormone (progesterone).

The periodic changes in these hormones are very dynamic, and these changes have been reported to not only influence women's conscious condition but also affect the frequency of occurrence of athletic injury ${ }^{3)}$. A previous study reported that female soccer players were more prone to injury during the menstrual phases compared with the rest of the menstrual cycle ${ }^{4}$ ). It has also been reported that anterior cruciate ligament injuries are more likely to occur

*Corresponding author. Hitomi Ubukata (E-mail: ubukata@ takasaki-u.ac.jp)

C2015 The Society of Physical Therapy Science. Published by IPEC Inc. This is an open-access article distributed under the terms of the Creative Commons Attribution Non-Commercial No Derivatives (by-ncnd) License $<$ http://creativecommons.org/licenses/by-nc-nd/3.0/> . during the menstrual phases when the levels of estrogen and progesterone are low ${ }^{5}$. In contrast, another report suggested an improvement in the handgrip, grip muscle test during the menstrual phases ${ }^{6}$. Furthermore, a study on female crosscountry skiers, reported the best times were recorded after ovulation and during the postmenstrual period ${ }^{7}$. Therefore, the relationship between the different phases of the menstrual cycle and physical performance remains unclear.

Recently, to improve performance of sports players prevent disability, there has been a trend towards performance of exercises for the deep parts of the muscles of the trunk. The trunk is the foundation for that function is extremities. If the function of this foundation decreased, dysfunction of extremities occurs. Since prior to the movement of the upper extremity and lower extremities transverse abdominal muscle is contracted, the stability of the lumbar spine is improved. However, it is unclear whether the muscular activity changes as a result of the influence of the ovarian hormone that fluctuates during menstrual cycle. In addition, change of condition due to the menstrual cycle is an important issue for coaching staff and female athletes who should be required good results in sport races. It is thought that it is necessary to determine whether the menstrual cycle influences the activity of the TrA to offer effective physical therapy for improvement of the prevention of physical difficulties and athletic performance. In this study, we examined the changes in the thickness of the TrA using on ultrasonic imaging diagnostic device for noninvasive functional assessment and physical therapy treatment in women. 


\section{SUBJECTS AND METHODS}

The subjects were 15 young healthy females (mean age $18.6 \pm 0.9$ years, mean height: $1.57 \pm 0.05 \mathrm{~m}$, mean weight: $53.0 \pm 6.4 \mathrm{~kg}$, and mean BMI: $21.4 \pm 1.9 \mathrm{~kg} / \mathrm{m}^{2}$ ) with regular menstrual cycles (Table 1). Subjects with complications stemming from orthopedic surgery, gynecological disorders, or chronic lower back pain or those whose menstrual cycle became irregular during the study period were excluded from the research. All subjects provided informed consent for participation in the study. All experimental procedures in this study were reviewed and approved by the Ethics Review Committee of the International Neuromuscular Joint Facilitation Laboratory (INJFL).

The menstrual cycles of the subjects were determined using a questionnaire, and the dates of the last 2 menstrual cycles were noted. For the purpose of this study, we assumed a 28-day cycle, with day 3 representing the menstrual phase, day 12 representing the follicular phase, and day 21 representing the luteal phase.

An ultrasound imaging apparatus (MyLab 25) equipped with an $8-\mathrm{MHz}$ linear expression probe was used for this study. The thickness of the TrA muscle was first measured in a supine position. The left and right sides were measured under 2 conditions: resting and contracting at the end of expiration. For measurements in the prone posture, the subjects bent their knees at an angle of $90^{\circ}$. To prevent pelvis retroversion and subject were instructed to keep a pressurized biofeedback apparatus at a constant pressure of $40 \mathrm{mmHg}$ between the bed and the lumbar region. The change in the TrA muscle was measured by ultrasonic imaging, with the subjects instructed to "tighten the stomach muscle by squeezing the anal muscle."

Ultrasound images of the TrA muscle were obtained with the transducer positioned just superior to the iliac crest along the midaxillary line (Fig. 1). The techniques outlined in the study by Teyhen et al. ${ }^{8}$, in which the middle of the stomach muscle was centered within the field of view, were employed. The thickness of the TrA muscle was measured at intervals of $0.1 \mathrm{~mm}$ with a caliper on ultrasound images. All measurements were taken by a single skilled person. Internal reproducibility and reliability were proven according to a previous study ${ }^{9)}$. The TrA muscle was measured 3 times, and the average of the thickness of the muscle on both sides was used for analysis. All images were collected at the end of normal exhalation to control for the influence of respiration. Muscle thickness was measured while maximum expiration was maintained for $5 \mathrm{~s}$.

Statistical analysis was performed using the Bonferroni method. Variations in the thickness of the TrA muscle according to the phase of the menstrual cycle were examined using the 2-way ANOVA for both conditions: at rest and on contraction. The significance level was chosen as 0.05 .

\section{RESULTS}

In the resting state, the thickness of the TrA muscle significantly increased compared with the thickness during contraction regardless of the menstrual cycle phase. Moreover, there were no significant differences in the variation
Table 1. General characteristics of the subjects

\begin{tabular}{lc}
\hline Variable & Value $(\mathrm{n}=15)$ \\
\hline Age $($ years $)$ & $18.60 \pm 0.9$ \\
Height $(\mathrm{m})$ & $1.57 \pm 0.05$ \\
Weight $(\mathrm{kg})$ & $53.0 \pm 6.4$ \\
BMI $\left(\mathrm{kg} / \mathrm{m}^{2}\right)$ & $21.4 \pm 1.9$ \\
\hline \multicolumn{2}{l}{ Mean \pm SD. BMI: body mass index }
\end{tabular}

Table 2. Thickness of the transversus abdominis muscle and variation rates at various stages of the menstrual cycle

\begin{tabular}{lccc}
\hline \multirow{2}{*}{$\begin{array}{c}\text { Menstrual } \\
\text { cycle }\end{array}$} & \multicolumn{2}{c}{$\begin{array}{c}\text { Thickness of the transversus } \\
\text { abdominis muscle }\end{array}$} & Variation rate \\
& $\begin{array}{c}\text { At rest } \\
(\mathrm{mm})\end{array}$ & $\begin{array}{c}\text { On contraction } \\
(\mathrm{mm})\end{array}$ & \\
\hline 3rd day & $2.65 \pm 0.68$ & $4.11 \pm 1.16 *$ & $1.70 \pm 0.52$ \\
12th day & $2.55 \pm 0.73$ & $4.44 \pm 0.86 *$ & $1.89 \pm 0.57$ \\
21st day & $2.41 \pm 0.58$ & $4.14 \pm 0.70 *$ & $1.73 \pm 0.41$ \\
\hline
\end{tabular}

Mean \pm SD. $* \mathrm{p}<0.05$

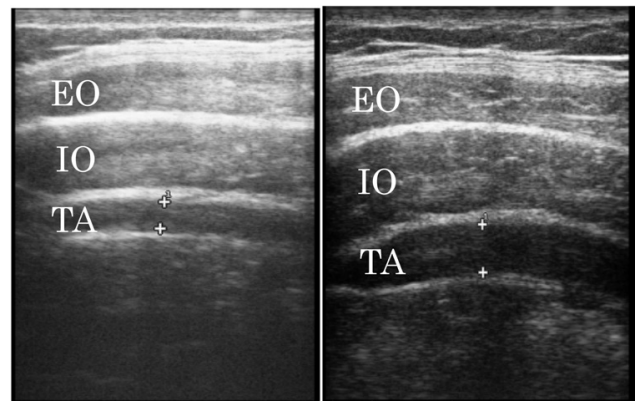

Fig. 1. Parasagittal section of the transversus abdominis muscle at rest (left) and on contraction (right)

EO: external oblique muscle; IO: internal oblique muscle; TA: transversus abdominis muscle

rates of the thickness of the TrA muscle in any phase of the menstrual cycle (Table 2).

\section{DISCUSSION}

In this study, we assumed that differences would exist in the thickness of the TrA muscle depending on the menstrual cycle. However, we did not observe any significant difference in the thickness of the TrA muscle, which was not associated with muscle contraction directly.

The menstrual cycle is closely regulated by the levels of the estrogenic hormone (estrogen) and the luteal hormone (progesterone). In has been suggested that estrogen assists in glucose uptake by the skeletal muscles during exercise, increases the lipid metabolism capacity, and inhibits blood coagulation $^{10,11)}$. On the other hand, it has been reported 
that progesterone increases the body temperature and the respiratory coefficient, controls the increase in heart rate, and activates skeletal muscle internal fatty acid enzymes ${ }^{12,13)}$.

Estrogen and progesterone have antagonistic effects. All these factors influence the exercise condition. It is possible that physical ability is influenced by different hormonal environments (i.e., the follicular phase versus the luteal phase). However, in our study, fluctuations in the sex hormones throughout the menstrual cycle did not affect the contractility and thickness of the TrA muscle.

TrA has a feed-forward action prior to the movement of the limbs. In this study, thickness of the TrA increased during contraction in comparison with the resting state. McMeeken et al. ${ }^{14)}$ reported the muscle activity and muscle thickness of the $\operatorname{Tr} A$ and showed a high correlation. In the present study, there was no change in muscle contraction in association with the menstrual cycle, as contraction of the TrA was possible regardless of the menstrual cycle; this suggested that muscle contraction is not affected by fluctuations in sex hormones. In a previous study, the fluctuation in sex hormones was reported to not affect muscle contraction ${ }^{15}$, and this supports the results of the present study. Strength and fatigue of muscle from that there is also reported that not related to the menstrual cycle, and women who regularly menstruating it is possible to exercise regardless of the menstrual cycle we thought. For the reasons stated above, there is little need to consider the menstrual cycle when measuring muscle thickness in physical therapy because the $\operatorname{Tr} A$ does not depend on the menstrual cycle. However, it has been reported that other factors in combination with the menstrual cycle, it is reported to exert an influence on athletic performance. Janse et al. ${ }^{16)}$ performed an progressive resistance exercise in two different environments, a high temperature and humidity environment (room temperature 32 degrees and humidity $60 \%$ ) and a normal environment (room temperature $20 \mathrm{de}$ grees and humidity $45 \%$ ). Time to fatigue was shortened by $5.7 \%$ in comparison with the early follicle period in the high temperature and humidity environment at the mid-luteal phase. In addition, it was reported that minute ventilation, heart rate and subjective exercise intensity in the maximum movement is also increased. Because the basal temperature rises due to the hyperthermic action of progesterone as in the case of the luteal phase, it is possible that the ventilator response rises until the luteal phase. Exercise in high temperature and humidity environment has the potential to influence performance. Chaecle et al. ascertained that all of their subjects had suffered from a high degree of menstrual pain and that such pain had decreased their everyday activities, affecting their daily lives ${ }^{17}$. In conclusion, there is a need for studies about conditioning that extend to psychological changes such as dysphoria, tension, and loss of motivation accompanying bleeding and menstrual pain.

\section{REFERENCES}

1) Kumiko T: Development acceleration-first menstrual period, height, and weight- of adolescence girl. Nagasaki Outside Large Theory Bush, 2010, $14,97-111$.

2) The Ministry of Education: Idea and how at school to advance sex education. Tokyo: Gyosei, 1999.

3) Noboru M: Medicine of female sports. Tokyo: Fumikagedou, 1997.

4) Möller-Nielsen J, Hammar M: Women's soccer injuries in relation to the menstrual cycle and oral contraceptive use. Med Sci Sports Exerc, 1989, 21: 126-129. [Medline]

5) Slauterbeck JR, Fuzie SF, Smith MP, et al.: The menstrual cycle, sex hormones, and anterior cruciate ligament injury. J Athl Train, 2002, 37: 275-278. [Medline]

6) Davies BN, Elford JC, Jamieson KF: Variations in performance in simple muscle tests at different phases of the menstrual cycle. J Sports Med Phys Fitness, 1991, 31: 532-537. [Medline]

7) Fomin SK, Pivovarova VI, Voronova VI: Changes in the special working capacity and mental stability of well- trained woman skiers at various phases of the biological cycle. Sports Train Med Rehabil, 1989, 1: 89-92. [CrossRef]

8) Teyhen DS, Miltenberger CE, Deiters HM, et al.: The use of ultrasound imaging of the abdominal drawing-in maneuver in subjects with low back pain. J Orthop Sports Phys Ther, 2005, 35: 346-355. [Medline] [CrossRef]

9) Panjabi MM: The stabilizing system of the spine. Part I. Function, dysfunction, adaptation, and enhancement. J Spinal Disord, 1992, 5: 383-389, discussion 397. [Medline] [CrossRef]

10) Naessen T, Rodriguez-Macias K, Lithell H: Serum lipid profile improved by ultra-low doses of 17 beta-estradiol in elderly women. J Clin Endocrinol Metab, 2001, 86: 2757-2762. [Medline]

11) Chen FP, Lee N, Wang $\mathrm{CH}$, et al.: Effects of hormone replacement therapy on cardiovascular risk factors in postmenopausal women. Fertil Steril, 1998, 69: 267-273. [Medline] [CrossRef]

12) Hessemer V, Brück K: Influence of menstrual cycle on thermoregulatory, metabolic, and heart rate responses to exercise at night. J Appl Physiol 1985, 1985, 59: 1911-1917. [Medline]

13) Seebauer M, Frühwirth M, Moser M: Changes of respiratory sinus arrhythmia during the menstrual cycle depend on average heart rate. Eur $\mathrm{J}$ Appl Physiol, 2002, 87: 309-314. [Medline] [CrossRef]

14) McMeeken JM, Beith ID, Newham DJ, et al.: The relationship between EMG and change in thickness of transversus abdominis. Clin Biomech (Bristol, Avon), 2004, 19: 337-342. [Medline] [CrossRef]

15) Lebrun CM, McKenzie DC, Prior JC, et al.: Effects of menstrual cycle phase on athletic performance. Med Sci Sports Exerc, 1995, 27: 437-444. [Medline] [CrossRef]

16) Janse DE, Jonge XA, Thompson MW, et al.: Exercise performance over the menstrual cycle in temperate and hot, humid conditions. Med Sci Sports Exerc, 2012, 44: 2190-2198. [Medline] [CrossRef]

17) Lim C, Park Y, Bae Y: The effect of the kinesio taping and spiral taping on menstrual pain and premenstrual syndrome. J Phys Ther Sci, 2013, 25: 761-764. [Medline] [CrossRef] 